\title{
Effects of aging on visuospatial attention: an ERP study
}

\author{
Tim Curran ${ }^{\mathrm{a}, *}$, Alex Hills ${ }^{\mathrm{a}}$, Marian B. Patterson ${ }^{\mathrm{a}, \mathrm{b}, \mathrm{c}, \mathrm{d}}$, Milton E. Strauss ${ }^{\mathrm{a}, \mathrm{b}}$ \\ ${ }^{a}$ Department of Psychology, Case Western Reserve University, Cleveland, OH, 44106-7123, USA \\ ${ }^{\mathrm{b}}$ Alzheimer Center of University Hospitals and Case Western Reserve University, Cleveland, OH, 44120, USA \\ ${ }^{\mathrm{c}}$ Department of Neurology, Case Western Reserve University, Cleveland, OH, 44106-5000, USA \\ ${ }^{\mathrm{d}}$ Department of Psychiatry, Case Western Reserve University, Cleveland, OH, 44106-5080, USA
}

Received 7 April 2000; received in revised form 3 May 2000; accepted 27 July 2000

\begin{abstract}
The effects of aging on visuospatial attention were investigated with event-related brain potentials (ERPs). A central arrow pointed towards ( $75 \%$ valid cues) or away from ( $25 \%$ invalid cues) the location of upcoming visual targets to which subjects made two choice discriminations. Young and older adults responded faster following valid than invalid cues. The absolute magnitude of the cueing effect was larger for older than young subjects, but cueing effects were similar between groups when estimated proportionally to overall response time. Under the present conditions, the electrophysiological manifestations of visuospatial attention were similar for young and older adults. Early ERP components following the target stimulus (P1, N1, Nd1) were slower for older than young subjects, but amplitude was similarly affected by cueing in each group. The temporal correspondence between component latencies and the observed cueing effects are consistent with theories positing that attention amplifies the sensory gain of early perceptual processes. The observation that aging slowed latency of the ipsilateral but not the contralateral $\mathrm{P} 1$, is consistent with age differences in interhemispheric transfer times. A broadly distributed $200-400 \mathrm{~ms}$ validity effect on ERP amplitude was similar between groups in timing, spatial distribution, and magnitude. The 200-400 ms attention effect appeared to be a modulation of the P3 in younger subjects, as earlier observed. However, the present study dissociated the $200-400 \mathrm{~ms}$ attention effects from the P3 component because the P3 did not peak until $526 \mathrm{~ms}$ in older subjects. (C) 2001 Elsevier Science Ltd. All rights reserved.
\end{abstract}

Keywords: Event-related potentials; Evoked potentials; Slowing; Vision; Interhemispheric transfer

\section{Introduction}

Our visual environment often confronts us with more information than our brain can fully process. Visual attention enables us to preferentially process information from a selected location or object (reviewed in [49,50]). Behavioral research has investigated the effects of adult aging on visuospatial attention, but the results have been somewhat mixed. Research with young subjects has shown that event-related brain potentials (ERPs) can provide useful information about visuospatial attention processes (reviewed in $[18,43]$ ). In the present research, we used ERP measures to further our understanding of how aging impacts visuospatial attention.

\footnotetext{
* Corresponding author. Present address: Department of Psychology, University of Colorado, Campus Box 345, Boulder, CO, 803090345, USA. Tel.: + 1-303-4925040; fax: + 1-303-4922967.

E-mail address: curran@psych.colorado.edu (T. Curran).
}

Posner and colleagues developed a simple task for studying visuospatial attention $[54,56]$. Each trial begins with the presentation of a cue that directs attention towards the possible location of an upcoming peripheral target. Valid cues direct attention to the correct target location whereas invalid cues direct attention to an incorrect location. Faster response times (RTs) to targets following valid than invalid cues ('cue validity effects') are considered indicative of attentional processes. The attentional processes are typically considered 'covert' because subjects are told to avoid eye movements and maintain a central visual focus through the cue and target periods. Cue validity effects vary with the duration between cue and target onsets (stimulus onset asynchrony, SOA) and the nature of the cue (e.g. $[35,46,55,68])$. Spatially informative peripheral cues at potential target locations are thought to engage involuntary, automatic, exogenous attention processes. 
Centrally located symbolic cues (e.g. arrows) depend upon voluntary, endogenous processes. Cueing effects tend to be maximal at shorter SOAs for peripheral cues, but maximal at longer SOAs for central cues.

Posner's task has been used to study the effects of adult aging on visuospatial attention, but the results have been somewhat inconsistent. Some investigators have reported that aging affects attention with central cues more than with peripheral cues $[4,19,23,25]$, but one group has reported the opposite pattern (with short SOAs: $100-350 \mathrm{~ms}$, [38]). Under central cueing conditions age-related deficits are more often observed with short than long SOAs [4,25,31]. Other studies have found similar cueing effects for older and young subjects at short SOAs, but larger cueing effects for older than young adults at longer SOAs [23,25]. Greenwood et al. [23] found that validity effects increased with age only for a two choice RT task at long SOAs (500 and $2000 \mathrm{~ms})$, but not for a shorter SOA (200 ms) or a simple target detection task (all SOAs). Folk and Hoyer [19] observed larger validity effects for young than older adults when the cue was a small central arrow, but no group differences, when a larger arrow was slightly shifted towards the pointed direction (SOAs between 50 and $250 \mathrm{~ms}$ ). In summary, many variables influence the measurement of age-related changes in attention, but it is difficult to reach clear general conclusions.

Slower responding by older than young subjects could also contribute to the ambiguity of earlier research. Age-related slowing of information processing has figured prominently in theoretical accounts of cognitive aging (e.g. $[7,47,58])$. In addition to theoretical indications that processing speed influences cognitive processes, there are measurement problems associated with comparison of groups differing on overall performance [8]. Chapman et al. [8] showed that the expected value of a RT difference score (e.g. invalid RT-valid RT) increases with overall RT. Thus, RT difference scores tend to be larger for slow than fast individuals or groups.

Overall slowness effects have been recognized, at least implicitly, in studies of age-related changes in attention that have measured validity effects proportionally to overall response time ([RT $\left.\mathrm{R}_{\text {Invalid }}-\mathrm{RT}_{\text {Valid }}\right] /$ $\left.\mathrm{RT}_{\text {Valid }},[25,62]\right)$. However, proportions only correct for slowing if it is assumed that the regression of the difference score on overall slowness is linear with an intercept of zero [8]. One study suggested that age-related slowing contributed to as much as $93 \%$ of the variance in the validity effects observed with central cues [38]. Lincourt et al. [38] constructed a Brinley plot in which condition means of young and older groups are plotted against each other [3]. Lincourt et al. [38] plotted 10 means (valid at 5 SOAs + invalid at 5 SOAs) that were fit by a regression line accounting for $93 \%$ of the variance. Regression analyses (including Brinley plots and proportions) are limited because they provide no means for differentiating between slowing effects attributable to processing differences versus measurement artefact. ERP indices of attention may be useful because they sidestep problems associated with the measurement of RT differences.

Event-related brain potentials (ERPs) are sensitive to cue validity in variants of Posner's spatial cueing task (reviewed in $[18,43]$ ). Most studies have recorded ERPs that coincide with processing of the target rather than the cue (exceptions include [24,67]), so hereafter ERPs can be assumed to be target-related unless otherwise specified. Mangun and Hillyard [41] found that the validity of central cues impacted the P1 and N1 components recorded over occipital scalp regions in conjunction with target presentation. P1 and N1 are the earliest positive amplitude (P1: about $100 \mathrm{~ms}$ after stimulus onset) and negative amplitude (N1: about $160 \mathrm{~ms}$ ) ERP components that are reliably elicited by visual stimuli. The P1 and N1 are generally thought to reflect activity of early perceptual processes, so associated validity effects suggest that visuospatial selection can occur at relatively early stages of visual information processing $[27,39,41]$. The P1 validity effect has been observed in both simple (speeded detection) and two choice (discriminitive responding) conditions, but the $\mathrm{N} 1$ effect is only observed with discriminitive responding $[44,41]$. Therefore, the P1 may reflect earlier stages of visual analysis than the N1. In turn, the N1 may index visual identification processes $[27,44,41]$. Based on studies coregistering ERPs with PET, it is been proposed that the P1 originates from ventral, extrastriate visual cortex $[26,45]$. Localization of the N1 generator is less certain, but the $\mathrm{N} 1$ attention effect, like the P1, is specific to the visual modality, so a visual cortical locus is likely [18]. In contrast, two other attention-related negative differences are similar in visual and auditory modalities ( $\mathrm{Nd} 1$ and $\mathrm{Nd} 2,[18]) . \mathrm{Nd} 1$ is a greater negativity following invalid than valid cues that is maximal over midline centroparietal recording sites $(\mathrm{Cz}, \mathrm{Pz})$ between 140 and $190 \mathrm{~ms}[17,18] . \mathrm{Nd} 2$ is a greater negativity following invalid than valid cues that is distributed more frontally between 220 and $300 \mathrm{~ms}[17,18]$. The $\mathrm{Nd} 2$ is part of a broader 'late positive deflection' that also includes the P300. P300 amplitude typically is more positive for invalid than valid conditions $[17,41]$.

The goal of the present research was to investigate age-related changes in attention by measuring ERPs during Posner's covert spatial cueing task. Earlier research indicates that aging effects vary with a number of experimental variables (e.g. SOA, central versus peripheral cues, simple versus choice RT). Choice of the present design parameters was primarily based on similarity to other studies recording reliable ERP effects $[17,41]$. Thus, the current experiment used a central 
arrow cue, $795 \mathrm{~ms}$ SOA, and a two choice target discrimination task. Given these task parameters, we will briefly review the results of aging studies with similar designs. In two experiments no differences were detected between the RT validity effects of older and young adults (SOA $=800 \mathrm{~ms}$ [4]; and $750 \mathrm{~ms}$ [31]). Two other groups found that invalid-valid RT differences were larger for older than young subjects (both SOAs $=500$ [23,25]). Hartley et al. [25] additionally reported that cueing effects were larger for older than young adults when expressed as a proportion of valid RTs. Thus, under the present conditions, RT attention effects have been unaffected or enhanced by aging.

\section{Method}

\subsection{Subjects}

Two groups of right-handed subjects participated in the experiment. Young subjects were 24 students at Case Western Reserve University (12 males, 12 females; mean age \pm S.D. $=23.2 \pm 4.4$ years, range: $18-36$ years). Young subjects participated to fulfill an introductory psychology research requirement or were graduate student volunteers. Older subjects were 30 healthy individuals (11 males, 19 females; $71.6 \pm 7.1$ years, range: $57-84$ years) recruited from the community and the Research Registry of the Alzheimer Center (UAC) of University Hospitals and Case Western Reserve University. Older subjects were paid $\$ 30$ for their participation. Mini-Mental State Examination (MMSE, [20]) scores for 22 of the 30 older subjects were available from the UAC database (mean MMSE score \pm S.D. $=29.0 \pm 1.0$, range: $26-30$ ).

Subjects were discarded because of excessive eye movements or EEG recording problems (as detailed in 'EEG Data Reduction') and testing continued until 16 acceptable subjects were obtained in each group. The mean age ( \pm S.D.) of the 16 young subjects was $22.4 \pm$ 4.0 years (range: 18-30 years; nine males, seven females). The 16 older subjects were $69.8 \pm 7.8$ years old (range: 57-84 year; seven males, nine females). The mean acuity for the sample of older subjects for which there was usable data was $20 / 46 \pm 22$, range: $20 / 20-20 /$ 100. MMSE scores were available for 12 of the 16 older subjects with usable data $(29.2 \pm 0.8$, range: $28-30)$.

\subsection{Design and procedure}

Each session lasted approximately $1.5-2$ h. After obtaining informed consent, the Lighthouse Near Visual Acuity Test (second edn., Lighthouse, 1992) was administered to all older subjects (from $40 \mathrm{~cm}$ ). Next, the subjects were given instructions for the experimental task and completed a block of practice trials. Applica- tion of the Geodesic Sensor Net followed the practice.

Each trial included a central arrow (left or right) that was followed by a peripheral target (square or circle). The arrow pointed towards the upcoming target location on valid trials $(75 \%)$ and in the opposite direction on invalid trials $(25 \%)$. Subjects were asked to maintain central fixation and press one of two response keys, according to the target identity.

Event timing was synched to the refresh cycle of the display monitor (15 ms per cycle). The trial events occurred in the following order (event duration in $\mathrm{ms}$ ), (1) central fixation cross (randomly varying from 225 to $590 \mathrm{~ms}$ ); (2) central arrow (300 ms); (3) central dot (495 $\mathrm{ms})$; (4) peripheral target (105 ms). A 2 s EEG collection epoch began $195 \mathrm{~ms}$ prior to arrow onset. The cue-target onset asynchrony (SOA) was $795 \mathrm{~ms}$. Eight within-subject conditions were obtained by combining - two arrow directions (left, right), two target locations (left visual field (LVF), right visual field (RVF)), and two targets (square, circle). The arrow pointed towards the subsequent target location on valid trials, and pointed in the opposite direction on invalid trials. Each arrow, location, and target type occurred equally often in valid and invalid conditions.

The experiment included 24, 17-trial blocks. Since movement artefact is common at the beginning of each block, the first trial of each block (randomly selected from one of the valid conditions) was not included in analyses. Of the remaining 16 trials, 12 were valid and four invalid. Thus, cues were valid on $75 \%$ of trials (76\% including the first valid trial of each block). Presentation order was randomly determined with the constraint that no more than three consecutive trials occurred in the same arrow $\times$ location $\times$ target condition.

Subjects responded with the first two fingers of the right hand on two vertically aligned response keys. They pressed one key for squares and another for circles. Assignment of response keys (lower, upper) to targets (circle, square) was counterbalanced across subjects. Subjects were instructed to avoid blinking or unnecessary movement, keep their eyes fixed on the center of the screen, and press the correct key as quickly and accurately as possible. Subjects were informed that the arrow would sometimes point towards the location of the upcoming target and other times would point in the opposite direction.

\subsection{Stimuli and apparatus}

Stimulus presentation and response collection were controlled by a Macintosh computer and a 14 in. Apple Multiscan Color Monitor. White stimuli were projected onto a black background. Viewing distance was $45 \mathrm{~cm}$. Circles (radius $=0.5 \mathrm{~cm}$, area $=0.79 \mathrm{~cm}^{2}$, visual angle $\left.=1.1^{\circ}\right)$ and squares $\left(\right.$ side $=0.9 \mathrm{~cm}$, area $=0.84 \mathrm{~cm}^{2}$, 
Table 1

Mean accuracy $(P[\mathrm{acc}])$ and response time $(\mathrm{RT}, \mathrm{ms})$

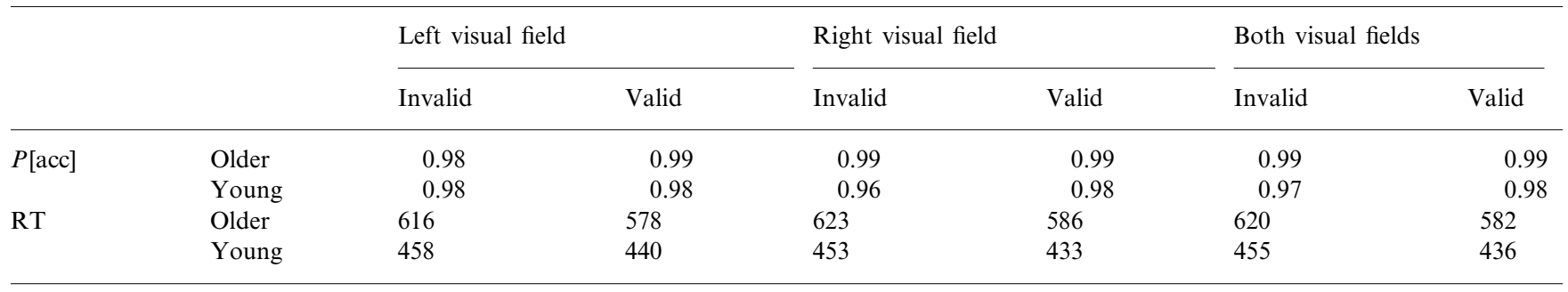

visual angle $=1.0^{\circ}$ ) were similar sizes. The central dot (appearing between cue and target) illuminated a $4 \times 4$ square of pixels (side $=0.14 \mathrm{~cm}$, area $=0.02 \mathrm{~cm}^{2}$, visual angle $=0.2^{\circ}$ ). The fixation cross was $0.60 \mathrm{~cm}$ in height and width (visual angle $=0.8^{\circ}$ ). The central arrow was $1.31 \mathrm{~cm}$ wide (visual angle $=1.7^{\circ}$ ) and $0.84 \mathrm{~cm}$ high (visual angle $=1.0^{\circ}$ ). Peripheral targets were $6.5^{\circ}$ horizontal from the screen center. Stimuli were presented approximately at eye level vertically.

Scalp voltages were collected with a 128-channel Geodesic Sensor Net ${ }^{\mathrm{TM}}$ [63] connected to an AC-coupled, 128-channel, high input impedance amplifier (200 $\mathrm{M} \Omega$, Net $\mathrm{Amps}^{\mathrm{TM}}$, Electrical Geodesics Inc., Eugene, OR). Amplified analog voltages $(0.1-100 \mathrm{~Hz}$ bandpass $)$ were digitized at $250 \mathrm{~Hz}$. Recorded voltages were referenced to a vertex channel. Individual sensors were adjusted until impedances were less than $50 \mathrm{k} \Omega$.

\subsection{EEG data reduction}

ERPs were computed for each subject in four primary experimental conditions (collapsing across circle and square targets): valid/LVF, valid/RVF, invalid/ LVF, invalid /RVF. Post-target ERP activity was of primary interest, pre-target activity was used to monitor eye movements. ERPs were baseline-corrected with respect to a $100 \mathrm{~ms}$ pre-target interval and digitally low-pass filtered at $40 \mathrm{~Hz}$. An average-reference transformation was used to minimize the effects of referencesite activity and accurately estimate the scalp topography of the measured electrical fields $[2,10,11,37,51,64]$.

Only correct trials were included in the ERPs. Trials were dropped from ERP averaging if they contained eye movements (vertical or horizontal EOG channel differences greater than $70 \mu \mathrm{V}$ ) or more than five bad channels (changing more than $50 \mu \mathrm{V}$ between samples, or reaching amplitudes over $100 \mu \mathrm{V}$ ). Trials with pretarget saccades were rejected if the horizontal EOG (HEOG) was greater than $70 \mu \mathrm{V}$. Data from individual channels that were consistently bad for a given subject were replaced using a spherical interpolation algorithm [61]. The median number of replaced channels was 1.00 for young subjects $($ mode $=1$, range $=0-2)$ and 2.00 for older subjects $($ mode $=2$, range $=0-3$ ). A nonparametric Mann-Whitney $U$ test indicated that the number of bad channels did not significantly differ between groups $(U=93.50, P=0.19)$.

Data from eight young $(33 \%)$ and 14 older $(47 \%)$ subjects were discarded. Most of these subjects were excluded because pre-target ERPs indicated consistent lateral eye movements towards the arrow direction (older, $n=10$; young, $n=4$ ). These subjects were identified by visual inspection of the pre-target waveforms - showing divergent voltages for leftward and rightward arrows over HEOG channels (125 and 128, located over the right and left frontal processes of the zygomatic bones). HEOG to leftward and rightward arrows was calculated for the remaining subjects as the difference between channels 125 and 128. Mean HEOG within the cue-onset to target-onset period was $1.13 \mu \mathrm{V}$ for older subjects (S.D. $=0.71$, range: $0.20-2.70$ ) and $0.86 \mu \mathrm{V}$ for young subjects (S.D. $=1.01$, range: 0.20 $4.56)^{1}$. Subjects were also excluded if they had less than 16 acceptable trials within any of the four primary conditions (older, $n=4$; young, $n=4$ ). The mean number of acceptable trials per subject per condition was well above the 16-trial rejection criterion (young subjects: invalid/left $=33$, invalid/right $=33$, valid/left $=$ 96, valid/right $=97$; older subjects: invalid/left $=34$, invalid $/$ right $=35, \quad$ valid $/$ left $=102, \quad$ valid $/$ right $=101$ ).

\section{Results}

\subsection{Behavioral results}

Behavioral results are present in Table 1. Accuracy was high overall, but numerically higher for older subjects than young. To reduce the negative skew of the accuracy distribution, an arcsine transformation (2 arcsine $\sqrt{P}$ ) was applied to the proportion correct prior to

\footnotetext{
${ }^{1}$ One young subject with mean HEOG of $4.56 \mu \mathrm{V}$ was somewhat of an outlier (greater than 3.5 S.D. above the mean). The next highest mean for a young subject was $1.08 \mu \mathrm{V}$. Mangun and Hillyard [41] found that $1.08^{\circ}$ horizontal saccades resulted in mean HEOG amplitudes from 12 to $13 \mu \mathrm{V}$, so even this outlier showed mean HEOG well below a level indicating consistent eye movements towards the targets $\left(6.5^{\circ}\right.$ eccentricity in the present experiment).
} 
a group $\times$ cue (valid, invalid) $\times$ visual field ANOVA. There was a marginal group effect, $F(1,30)=3.06$, $\mathrm{MSE}=0.14, P=0.09$, and a significant three way interaction, $F(1,30)=4.21, \mathrm{MSE}=0.02, P<0.05$. The three-way interaction primarily reflected the observation that cue validity affected only young subjects' accuracy within the right visual field, though a post hoc $t$-test (young/RVF/valid versus young/RVF/invalid) was only marginally significant $(t(15)=2.03$, S.E. $=$ $0.05, P=0.06$, two tailed).

Reaction times were analyzed for only correct trials. Trials deviating by more than 3.5 S.D. from each subject's mean were excluded as outliers. A group $\times$ cue $\times$ visual field ANOVA indicated that young were faster than older subjects, $F(1,30)=26.32, M S E=$ $29170, P<0.001$. Subjects were faster on valid than invalid trials, $F(1,30)=54.85, \mathrm{MSE}=470, P<0.001$. The groups interacted with respect to both visual field, $F(1,30)=5.00, \mathrm{MSE}=308, P<0.05$; and cue, $F(1$, $30)=5.82, \quad \mathrm{MSE}=470, \quad P<0.05$. The young were faster responding to RVF than LVF targets, but older subjects showed the opposite pattern. When each group was considered separately, the small visual field differences were not significant (older: $F(1,15)=2.72$, $\mathrm{MSE}=351 ;$ young $=F(1,15)=2.29, \mathrm{MSE}=267$; both $P>0.10)$. In contrast, the cueing effect was highly significant for each group separately (older: $F(1,15)=$ 27.03, $\mathrm{MSE}=839$; young: $F(1,15)=57.82, \mathrm{MSE}=$ 101; both $P<0.001$ ).

The group by cue interaction suggested that the cueing effect was larger for older than young subjects. To minimize the influence of overall RT differences, proportional cueing scores were computed as

$P=\frac{\mathrm{RT}_{\text {invalid }}-\mathrm{RT}_{\text {valid }}}{\left(\mathrm{RT}_{\text {invalid }}^{*} P_{\text {invalid }}+\mathrm{RT}_{\text {valid }}^{*} P_{\text {valid }}\right)}$

The proportions $P_{\text {invalid }}$ and $P_{\text {valid }}$ were 0.25 and 0.75 . A group $\times$ visual field ANOVA on these proportional cueing scores (older in $\mathrm{LVF}=0.06$, older in $\mathrm{RVF}=$ 0.06 , young in $L V F=0.04$, young in $R V F=0.05$ ) resulted in no significant effects. Only the group effect approached significance, $F(1,30)=2.29, \mathrm{MSE}=0.003$, $P=0.14$.

\subsection{ERP results}

Analyses focused on ERP components that have been affected by visuospatial cueing in similar experiments (e.g. $[17,41])$. These studies have shown that the mean amplitude of the P1, N1, Nd1, Nd2, and P3 components differs between valid and invalid conditions. Electrode sites were chosen from earlier research. Peak latency analyses were conducted prior to amplitude analyses, and selection of amplitude windows was guided by the latency analyses (as detailed separately for each component). The peak latencies and mean amplitudes for the $\mathrm{P} 1, \mathrm{~N} 1$, and $\mathrm{P} 3$ components are shown in Table $2 . \mathrm{Nd} 1$ and $\mathrm{Nd} 2$ mean latencies are omitted from Table 2 because the component peaks were not identifiable in individual subjects, so means could not be computed. Alpha levels for ANOVAs were adjusted according to the conservative Geisser-Greenhouse procedure for sphericity violations [66].

\subsection{P1 component}

Mangun and Hillyard [41] found that the mean amplitude of the P1 (90-130 ms) was larger for valid than invalid conditions over left and right occipital recording sites (OL and OR). OL and OR approximately correspond to electrodes 65 and 91 (see Fig. 1). Due to the high spatial sampling density of the present experiments (i.e. 128 electrodes, approximately $2 \mathrm{~cm}$ apart), more reliable occipital ERPs were obtained by averaging across a number of nearby electrodes. OL + is defined as the ERP average of channels 58, 59, 64, 65, 66, 70, and $71 . \mathrm{OR}+$ is the ERP average of channels 84, 85, 90, 91, 92, 96, and 97. The visual fields (LVF, RVF) and hemispheres were combined into contralateral and ipsilateral conditions (following [17]). The contralateral condition averages across ERPs to RVF targets at $\mathrm{OL}+$ and $\mathrm{LVF}$ targets at $\mathrm{OR}+$. The ipsilateral condition averages across ERPs to RVF targets at OR + and LVF targets at $\mathrm{OL}+$. The contralateral and ipsilateral ERPs are plotted in Fig. 2.

A group (older, young) $\times$ cue $\times($ invalid, valid $) \times$ laterality (contralateral to target, ipsilateral to target) ANOVA was conducted on peak latencies (see Table 2). The contralateral $\mathrm{P} 1$ peaked earlier than the ipsilateral $\mathrm{P} 1, F(1,30)=212$, MSE $=170, P<0.001$; and the laterality effect interacted with group, $F(1,30)=10.51$, $\mathrm{MSE}=170, P<0.01$. The group by laterality interaction reflects the fact that aging affected the latency of the ipsilateral P1 (older subjects slower than young), but not the contralateral P1. The only other effect to approach significance was the cue by group interaction, $F(1,30)=2.93, \mathrm{MSE}=141, P=0.09$.

The group by laterality interaction indicates that aging significantly slowed the ipsilateral P1 but not the contralateral P1. This may indicate that the first source of age-related slowing occurred temporally between the contralateral P1 (92-96 ms peak latency) and the ipsilateral P1 (120-136 ms peak latency). Follow-up analyses were intended to better understand this interaction. Separate ANOVAs indicated slower ipsilateral P1 latency for older than young subjects, $F(1,30)=8.05$, $\mathrm{MSE}=266, P=0.01$, but age did not affect contralateral P1 latency, $F(1,30)=<1$, MSE $=346$. Comparing the MSE for the contralateral P1 (346) and the ipsilateral P1 (266) suggests that failure to detect a contralateral P1 difference could be attributable to greater variability. However, mean latency differences 
Table 2

Peak latencies and mean amplitudes for P1, N1, Nd1, Nd2, and P3 components ${ }^{\mathrm{a}}$

\begin{tabular}{|c|c|c|c|c|c|c|}
\hline Component & Group & Location & Cue & Peak lat. (ms) & Window (ms) & Mean amp. $(\mu \mathrm{V})$ \\
\hline \multirow[t]{5}{*}{$\mathrm{P} 1$} & \multirow[t]{3}{*}{ Older } & \multirow[t]{2}{*}{ Contralateral } & Invalid & 92 & $72-112$ & 0.36 \\
\hline & & & Valid & 96 & $76-116$ & 0.02 \\
\hline & & Ipsilateral & Valid & 136 & $116-156$ & 0.97 \\
\hline & \multirow[t]{2}{*}{ Young } & \multirow[t]{2}{*}{ Contralateral } & Invalid & 96 & $76-116$ & 0.47 \\
\hline & & & Valid & 96 & $76-116$ & 0.57 \\
\hline \multirow[t]{6}{*}{ N1 } & \multirow[t]{4}{*}{ Older } & \multirow[t]{2}{*}{ Contralateral } & Invalid & 192 & $152-232$ & -2.99 \\
\hline & & & Valid & 192 & $152-232$ & -3.33 \\
\hline & & \multirow[t]{2}{*}{ Ipsilateral } & Invalid & 200 & $160-240$ & -1.67 \\
\hline & & & Valid & 200 & $160-240$ & -1.88 \\
\hline & \multirow[t]{2}{*}{ Young } & \multirow[t]{2}{*}{ Contralateral } & Invalid & 180 & $140-220$ & -2.04 \\
\hline & & & Valid & 180 & $140-220$ & -2.16 \\
\hline \multirow{6}{*}{$\mathrm{Nd} 1$} & \multirow{2}{*}{ Older } & \multirow[t]{2}{*}{ RVF } & Invalid & & $148-208$ & 0.63 \\
\hline & & & Valid & & $148-208$ & 0.30 \\
\hline & \multirow[t]{4}{*}{ Young } & \multirow[t]{2}{*}{ LVF } & Invalid & & $140-200$ & 1.04 \\
\hline & & & Valid & & $140-200$ & 0.57 \\
\hline & & \multirow[t]{2}{*}{ RVF } & Invalid & & $140-200$ & 0.94 \\
\hline & & & Valid & & $140-200$ & 0.60 \\
\hline \multirow[t]{6}{*}{$\mathrm{Nd} 2$} & \multirow[t]{4}{*}{ Older } & \multirow[t]{2}{*}{ LVF } & Invalid & & $280-340$ & 3.41 \\
\hline & & & Valid & & $280-340$ & 2.22 \\
\hline & & \multirow[t]{2}{*}{ RVF } & Invalid & & $280-340$ & 3.00 \\
\hline & & & Valid & & $280-340$ & 2.16 \\
\hline & Young & LVF & Invalid & & $220-280$ & 3.34 \\
\hline & & & Valid & & $220-280$ & 2.03 \\
\hline & & RVF & Invalid & 372 & $272-472$ & 3.62 \\
\hline & & & Valid & 401 & $301-501$ & 3.15 \\
\hline
\end{tabular}

${ }^{a} \mathrm{P} 1$ and N1 statistics were averaged across left occipital $(\mathrm{OL}+=$ mean of channels 58, 59, 64, 65, 66, 70, and 71) and right occipital $(\mathrm{OR}+=$ mean of channels 84, 85, 90, 91, 92, 96, and 97) regions. Contralateral statistics were averaged across ERPs to RVF targets at OL + and LVF targets at $\mathrm{OR}+$. Ipsilateral statistics were averaged across ERPs to LVF targets at $\mathrm{OL}+$ and RVF targets at OR + . Nd1, Nd2, and P3 statistics were averaged across midline frontal (Fz+: mean of channels 5, 6, 11, 12), central $(\mathrm{Cz}+:$ mean of channels 7, 32, 55, 81, 107, VREF), and parietal (Pz+: mean of channels 61, 62, 67, 68, 73, 78, 79) regions. Peak lat., is peak latency. Window is the temporal interval used to calculate mean amplitude. Amp., is amplitude. LVF is left visual field. RVF is right visual field.

did not suggest a trend for age-related slowing of the contralateral P1 (older $=94 \mathrm{~ms}$, young $=96 \mathrm{~ms}$ ). The power $(1-\beta)$ of the present experiment to detect a contralateral P1 difference as large as the observed ipsilateral P1 difference was $0.82(\alpha=0.05)$.

Mean P1 amplitudes were computed within $40 \mathrm{~ms}$ windows that bounded the mean latencies in each condition (see Table 2). A group (older, young) $\times$ cue $\times($ invalid, valid $) \times$ laterality (contralateral, ipsilateral) ANOVA indicated that mean amplitude was more positive over the ipsilateral than contralateral hemisphere,
$F(1,30)=24.67, \mathrm{MSE}=0.59, P<0.001$. The cueing effect interacted with laterality such that P1 amplitude was higher for valid than invalid trials only over the ipsilateral hemisphere, $F(1,30)=8.67, \mathrm{MSE}=0.15$, $P<0.01$. The group $\times$ cue $\times$ laterality interaction approached significance, $F(1,30)=2.93, \mathrm{MSE}=0.15$, $P=0.10$.

Follow-up ANOVAs examined the contralateral and ipsilateral P1s separately. Cueing interacted across the groups for the contralateral P1, $F(1,30)=5.23$, $\mathrm{MSE}=0.14, P<0.05$. Within-group analyses suggested 


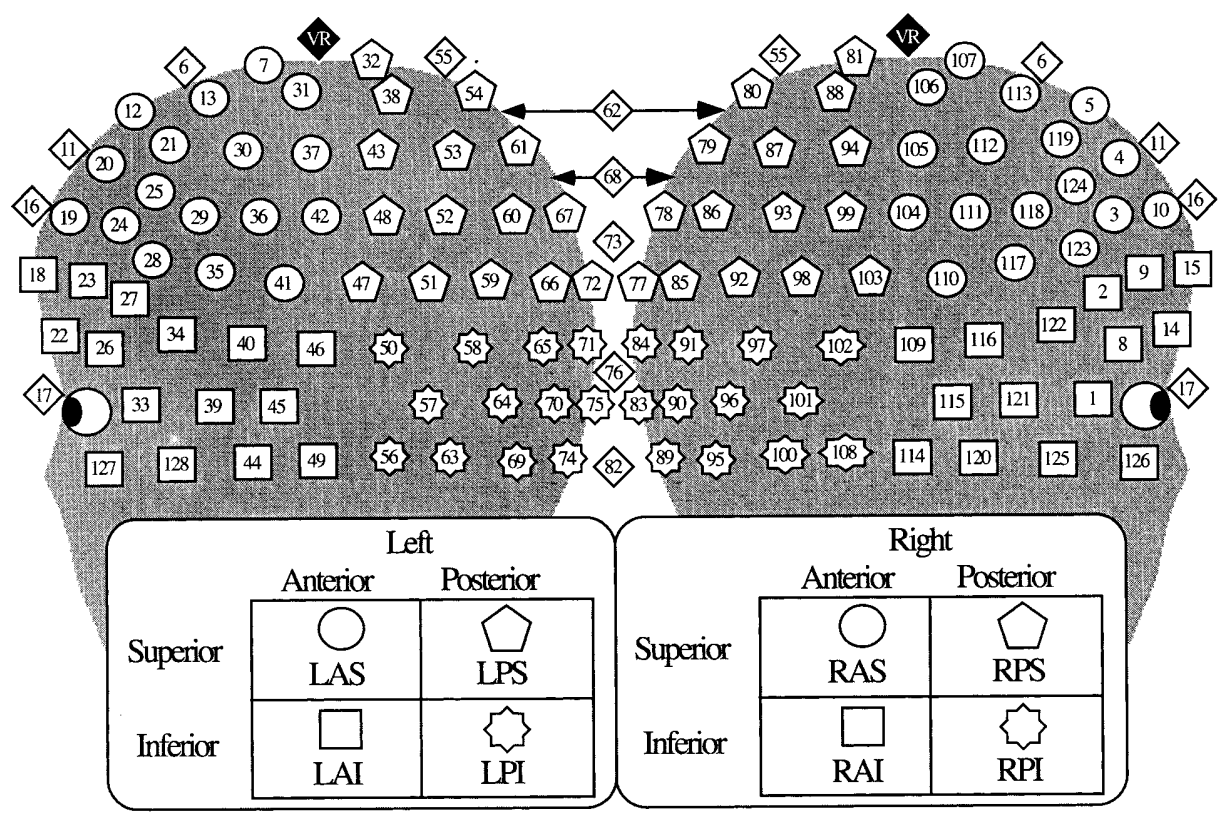

Fig. 1. Sensor locations on the 128-channel Geodesic Sensor Net. The approximate sensor locations were projected onto a 3D head model from which these 2D images were taken. Sensors appear more closely spaced at the edges because depth is lost in the 2D images, but actual electrode spacing is approximately equidistant throughout. Different symbols are used to denote channels within each of the eight spatial regions used in the 200-400 ms ANOVA. The tables define each symbol along with the abbreviations used for each region. Midline electrodes are denoted with diamond-shaped symbols. VR, vertex reference.

no validity effect for young $F(1,15)<1$, MSE $=0.18$; but the contralateral $\mathrm{P} 1$ was more positive to targets following invalid than valid cues for older subjects, $F(1$, $15)=8.70, \mathrm{MSE}=0.10, P<0.01$. This cueing effect was opposite of typically reported affects on the P1 (e.g. $[14,16,44,41])$. A validity effect appeared in the usual direction (valid $>$ invalid) for the ipsilateral P1, $F(1,30)=5.84, \mathrm{MSE}=0.22, P<0.05 ;$ and $\operatorname{did}$ not interact across the groups $(F<1)$.

\subsubsection{N1 component}

The $\mathrm{N} 1$ analyses also focused on the $\mathrm{OL}+$ and $\mathrm{OR}+$ regions (see Fig. 2). Peak latency was shorter for young than older subjects, $F(1,30)=9.00, \mathrm{MSE}=465$, $P<0.01$; and shorter contralaterally than ipsilaterally, $F(1,30)=27.90, \mathrm{MSE}=62, P<0.001$. No other effects approached significance (all $F<1$ ).

Mean N1 amplitudes were computed within $40 \mathrm{~ms}$ windows bounding the mean latencies in each condition (see Table 2). The N1 was more negative following valid than invalid cues, $F(1,30)=4.82, \mathrm{MSE}=0.28$, $P<0.05$, and more negative contralaterally than ipsilaterally, $F(1,30)=56.85, \mathrm{MSE}=0.67, P<0.001$. The cueing effect marginally interacted across with laterality, $F(1,30)=3.90$, MSE $=0.67, P=0.06$. Considered separately, the contralateral cueing effect was significant, $F(1,30)=5.24, \mathrm{MSE}=0.16, P<0.05$; but the ipsilateral cueing effect was not, $F(1,30)=2.29$, $M S E=0.23, P=0.14$. The group $\times$ cue interaction did not approach significance, $F(1,30)<1, \mathrm{MSE}=0.28$.

\subsubsection{Nd components}

Eimer [14,17] has identified $\mathrm{Nd} 1$ and $\mathrm{Nd} 2$ components that are more negative for valid than invalid conditions at midline electrodes $(\mathrm{Pz}, \mathrm{Cz}, \mathrm{Fz})$. The $\mathrm{Nd} 1$ has been reported to be maximal at the midline parietal $(\mathrm{Pz})$ and central sites $(\mathrm{Cz})$ between about 140 and 190 ms. The $\mathrm{Nd} 2$ has been recorded over these same sites but is also frontally prominent $(\mathrm{Fz})$ between about 220 and $300 \mathrm{~ms}$. Again, we capitalized on the high sampling density of the 128-channel Net to define local electrode groups that approximated $\mathrm{Fz}(\mathrm{Fz}+$ : mean of channels $5,6,11,12), \mathrm{Cz}(\mathrm{Cz}+$ : mean of channels 7, 32, 55, 81, 107, VREF), and $\mathrm{Pz}(\mathrm{Pz}+$ : mean of channels 61, 62, 67, 68, 73, 78, 79; see Fig. 1).

The $\mathrm{Nd} 1$ and $\mathrm{Nd} 2$ components were identified by visual inspection of the grand average ERPs (Fig. 3). Corresponding valid-invalid difference waveforms are shown in Fig. 4 (averaged across left and right visual fields). For young subjects, the timing of the present Nd1 (140-200 ms) and Nd2 (220-280) windows corresponded well with earlier reports [14,17]. We had no a priori basis for temporally delineating the $\mathrm{Nd}$ component in older subjects. Visual inspection suggested a slightly delayed N1d (148-208 ms) and a considerably delayed Nd2 (280-340 ms). Formal latency analyses were not attempted because these components were not clearly identifiable in individual subjects (hence, the omission of mean latencies from Table 2).

A group $\times$ cue $\times$ visual field $\times$ location $(\mathrm{Pz}+, \mathrm{Cz}+$, $\mathrm{Fz}+$ ) ANOVA was conducted on mean Nd1 ampli- 
tudes. The present analyses included visual field as an independent variable rather than laterality (as for P1 and N1) because the $\mathrm{Nd}$ components are recorded over hemispheric midline locations. Nd1 was more negative following valid than invalid cues, $F(1,30)=23.28$, $\mathrm{MSE}=0.64, P<0.001$; and the cueing effect interacted across locations, $F(2,30)=7.20, \mathrm{MSE}=0.37, P<0.01$. The cueing effect was larger at $\mathrm{Pz}+$ and $\mathrm{Cz}+$ than $\mathrm{Fz}+$ (consistent with [17]). Group did not interact with cueing $(F<1)$.

A group $\times$ cue $\times$ visual field $\times$ location ANOVA was conducted on mean $\mathrm{Nd} 2$ amplitudes. $\mathrm{Nd} 2$ was more negative following valid than invalid cues, $F(1,30)=$ 93.83, $\mathrm{MSE}=1.20, P<0.001$; and the cueing effect tended to be larger for LVF than RVF targets, $F(1$, $30)=4.13, \mathrm{MSE}=0.67, P=0.05$. The cueing effect interacted across locations, $F(2,30)=14.86, \mathrm{MSE}=$ $0.44, P<0.001$, such that it was larger near $\mathrm{Fz}+$ and $\mathrm{Cz}+$ than $\mathrm{Pz}+$ (consistent with [17]). Finally, there was a significant cue $\times$ group $\times$ location interaction, $F(2,30)=5.29, \mathrm{MSE}=0.44, P<0.05$. The three way interaction implied that group differences in the $\mathrm{Nd} 2$

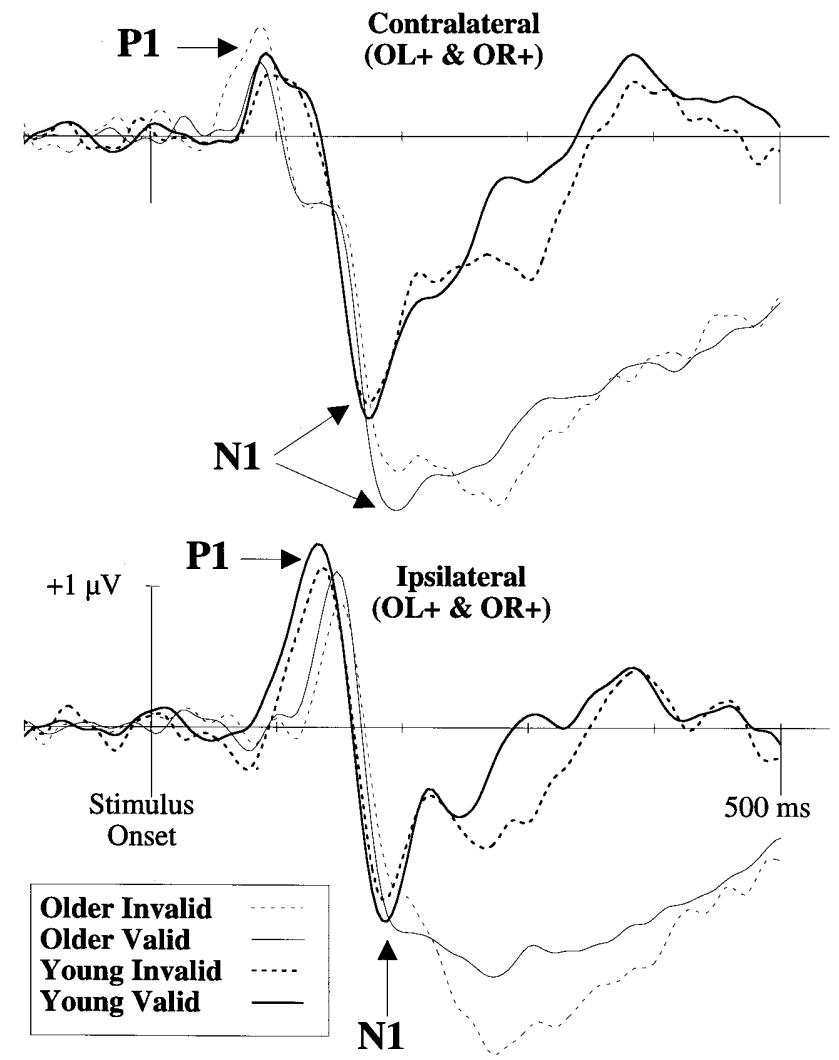

Fig. 2. Grand-average, average-referenced ERPs from left occipital $(\mathrm{OL}+=$ mean of channels $58,59,64,65,66,70$, and 71) and right occipital $(\mathrm{OR}+=$ mean of channels $84,85,90,91,92,96$, and 97) regions. The contralateral figure (top) averages across ERPs to RVF targets at $\mathrm{OL}+$ and $\mathrm{LVF}$ targets at $\mathrm{OR}+$. The ipsilateral figure (bottom) averages across ERPs to LVF targets at $\mathrm{OL}+$ and RVF targets at $\mathrm{OR}+$.

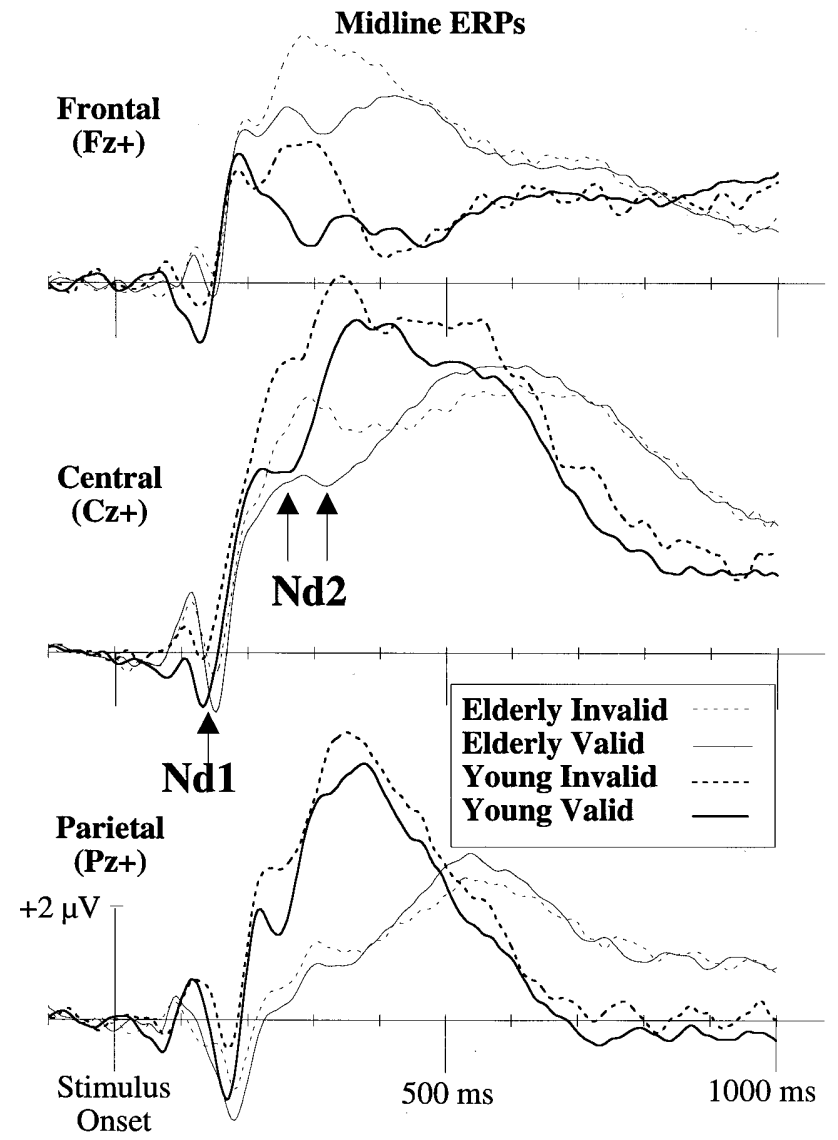

Fig. 3. Grand-average, average-referenced ERPs from midline frontal $(\mathrm{Fz}+$ : mean of channels 5, 6, 11, 12), central $(\mathrm{Cz}+$ : mean of channels 7, 32, 55, 81, 107, VREF), and parietal $(\mathrm{Pz}+$ : mean of channels 61, 62, 67, 68, 73, 78, 79) regions ERPs are averaged across LFV and RVF targets.

cueing effect varied across locations, so post hoc analyses compared valid-invalid voltage differences between groups at each location separately. The $\mathrm{Nd} 2$ cueing effect was marginally greater for older than young subjects at $\mathrm{Fz}+, t(30)=1.94$, S.E. $=0.25, P=0.06$; but marginally larger for young subjects at $\mathrm{Pz}+$, $t(30)=1.86$, S.E. $=0.27, P=0.07$. The groups did not differ at $\mathrm{Cz}, t(30)=1.08$, S.E. $=0.35$. Thus, the $\mathrm{Nd} 2$ cueing effect may have a slightly more anterior distribution in older subjects.

\subsubsection{P3 component}

Earlier research has found that P3 amplitude is more positive to targets that follow invalid than valid cues $[17,41]$. The $\mathrm{P} 3$ is typically maximal over centroparietal recording sites, but older subjects often show frontal P3 amplitudes that approach the magnitude of centroparietal voltages (reviewed in [21]). Therefore, P3 analyses were conducted on $\mathrm{Pz}+, \mathrm{Cz}+$, and $\mathrm{Fz}+$ regions (see Fig. 3). Initial latency analyses only included $\mathrm{Pz}+$ and $\mathrm{Cz}+$ because the older $\mathrm{P} 3$ was not clearly identifiable over $\mathrm{Fz}+$. Once P3 latency was estimated, $\mathrm{Fz}+$ was 
introduced in amplitude analyses to better characterize P3 caudality.

A group $\times$ cue $\times$ visual field $\times$ location $(\mathrm{Pz}+, \mathrm{Cz}+)$ ANOVA revealed that the $\mathrm{P} 3$ peaked earlier for young than older subjects, $F(1,30)=27.02, \mathrm{MSE}=42459$, $P<0.001$; and earlier for invalid than valid conditions, $F(1,30)=12.40, \mathrm{MSE}=4625, P<0.01$. Relevant mean latencies are shown in Table 2. Visual field and location interacted, $F(1,30)=5.20, \mathrm{MSE}=2181, P<0.05$; as did visual field $\times$ location $\times$ group, $F(1,30)=9.44$, $\mathrm{MSE}=2181, P<0.01$. The three way interaction suggested that the visual field effect was only present for young subjects, but the young subjects' visual field effect differed in polarity from $\mathrm{Cz}+(\mathrm{RVF}<\mathrm{LFV})$ to $\mathrm{Pz}+(\mathrm{LVF}<\mathrm{RVF})$.

Mean P3 amplitudes were computed within $200 \mathrm{~ms}$ windows bounding the mean latencies in each condition (see Table 2). A group $\times$ cue $\times$ visual field $\times$ location $(\mathrm{Pz}+, \mathrm{Cz}+, \mathrm{Fz}+)$ ANOVA did not result in a significant main effect for cue type, $F(1,30)=2.88$, MSE $=$ $0.62, \quad P=0.10$. However, the cue $\times$ group $(F(1$, $30)=17.57, \mathrm{MSE}=0.62, P<0.001)$, group $\times$ location $(F(2,30)=7.02, \mathrm{MSE}=0.62, P<0.001)$, and cue $\times$ group $\times$ location $(F(2,30)=5.68, \mathrm{MSE}=13.50, P<$ $0.01)$ interactions were significant.

Further ANOVAs concentrated on each group separately to clarify the nature of these interactions. Young

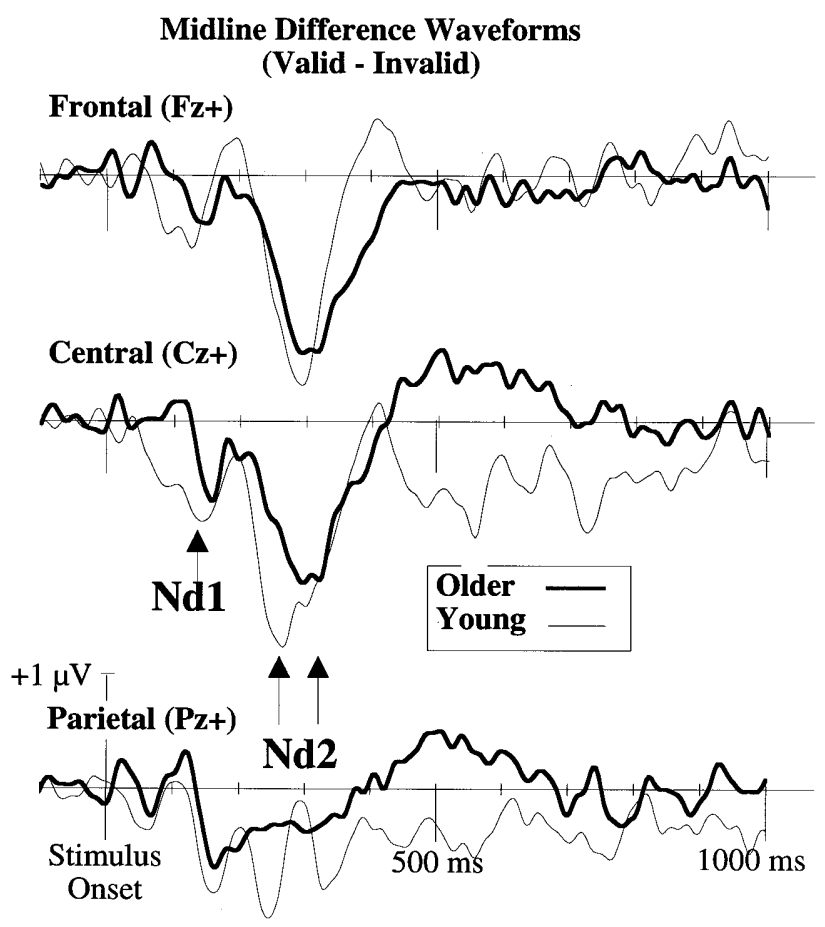

Fig. 4. Grand-average differences waveforms created by subtracting invalid from valid ERPs for the midline frontal $(\mathrm{Fz}+$ : mean of channels $5,6,11,12)$, central $(\mathrm{Cz}+$ : mean of channels $7,32,55,81$, 107, VREF), and parietal ( $\mathrm{Pz}+$ : mean of channels 61, 62, 67, 68, 73, $78,79)$ regions. Difference waveforms are averaged across LFV and RVF targets.

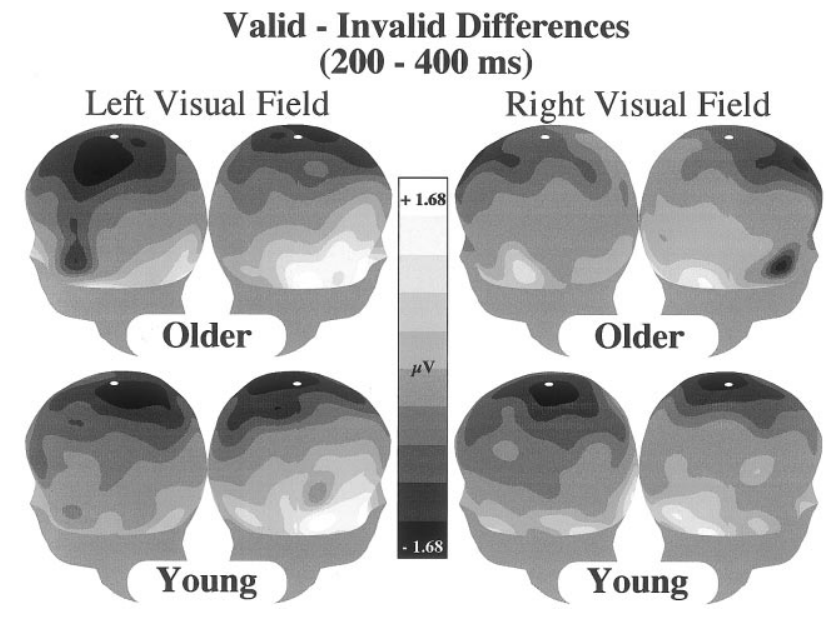

Fig. 5. Topographic distributions of ERP differences between valid and invalid conditions between 200 and $400 \mathrm{~ms}$. Contours change in $0.34 \mu \mathrm{V}$ steps. The top of each head is tilted forward with the vertex marked with a white spot.

subjects showed significant effects of cue type, $F(1$, $30)=27.57, \mathrm{MSE}=0.39, P<0.001$, and location, $F(2$, $30)=24.96, \mathrm{MSE}=13.46, P<0.001$. The cue $\times$ location interaction did not approach significance, $F(2$, $30)<1, \mathrm{MSE}=0.36$. P3 amplitude was smallest at $\mathrm{Fz}+(1.06 \mu \mathrm{V})$, larger at $\mathrm{Pz}+(3.92 \mu \mathrm{V})$, and largest at $\mathrm{Cz}+(5.59 \mu \mathrm{V})$. Invalid voltages were more positive than the valid voltages at all the three locations.

For older subjects, the main effect of cue type did not reach significance, $F(1,30)=2.27, \mathrm{MSE}=0.85, P>$ 0.10 . The location main effect $(F(2,30)=6.56, \mathrm{MSE}=$ $0.13 .55, P<0.01)$ and the cue $\times$ location interaction $(F(2,30)=5.60, \mathrm{MSE}=0.72, P<0.01)$ were significant. The P3 was larger at $\mathrm{Cz}+(4.52 \mu \mathrm{V})$ than $\mathrm{Fz}+$ $(2.67 \mu \mathrm{V})$ or $\mathrm{Pz}+(2.32 \mu \mathrm{V})$. The cueing effect conformed to the expected direction (invalid $>$ valid) only at $\mathrm{Fz}+$. Overall, the results suggest a smaller effect of cue validity on P3 amplitude for older than for the young subjects.

\subsubsection{Broadly distributed effects $(200-400 \mathrm{~ms})$}

The P1, N1, and Nd1 effects were clearly greatest over the regions specified in the foregoing analyses. P1 and $\mathrm{N} 1$ amplitudes were largest over $\mathrm{OL}+$ and $\mathrm{OR}+$. $\mathrm{Nd} 1$ was maximal over $\mathrm{Pz}+$ and $\mathrm{Cz}+$. In contrast, inspection of the global scalp topography suggested that the $\mathrm{Nd} 2$ and $\mathrm{P} 3$ were part of a more distributed pattern of cueing effects occurring between 200 and 400 ms. Fig. 5 shows the complete scalp topography of the cueing effects within this interval. Each head model was constructed by computing valid-invalid differences for each channel, interpolating the differences across a spherical head model, averaging the interpolations from 200 to $400 \mathrm{~ms}$, and projecting the average interpolated image onto a $3 \mathrm{D}$ head model. $\mathrm{Nd} 2$ is the most negative, superior, midline difference; but opposite going differ- 
ences are found over inferior regions. Opposite polarity differences are expected when the scalp surface is adequately sampled because surface-recorded potential fields are dipolar with equal positive and negative fields [48]. The $\mathrm{P} 3$ peaked during this $200 \mathrm{~ms}$ window for young subjects, but the $\mathrm{P} 3$ peaked later for older subjects. Thus, these broadly distributed differences contributed to the strong cue effects identified in the young $\mathrm{P} 3$ analysis, but would not have influenced the P3 analysis with older subjects in which cueing effects were weak.

To capture the broad spatial topography of the 200 $400 \mathrm{~ms}$ cueing effects, the measured head space was divided into eight spatial regions (see Fig. 1, following [9]); 2 hemispheres (left, right) $\times 2$ caudal (anterior, posterior) $\times 2$ vertical (inferior, superior). Channels within each region were averaged together to construct eight regional ERPs (see Fig. 6 in which visual fields and hemispheres are averaged into contralateral and ipsilateral waveforms). Mean amplitudes (200-400 ms) were entered into a group $\times$ cue $\times$ visual field $\times$ hemisphere $\times$ caudal $\times$ vertical ANOVA. Only cueing effects are reported. Overall, voltages were more negative following invalid than valid cues, $F(1,30)=94.17, \mathrm{MSE}=0.01$, $P<0.001$. Cueing significantly interacted with a number of other variables; cue $\times$ hemisphere, $F(1,30)=7.70$, MSE $=0.72, P<0.01$; cue $\times$ vertical, $F(1,30)=64.72$, $\mathrm{MSE}=0.58, P<0.001$; cue $\times$ hemisphere $\times$ caudal, $F(1$, $30)=11.69, M S E=0.13, P<0.01$; cue $\times$ visual field $\times$ hemisphere $\times$ caudal, $\quad F(1,30)=10.67, \quad \mathrm{MSE}=0.44$, $P<0.01$. The four-way interaction primarily captured the observation that the right, inferior positive valid-invalid differences were anteriorly maximal for LVF stimuli, but posteriorly maximal for RVF stimuli (see Fig. 5). Two other interactions were marginally significant; cue $\times$ visual field $\times$ lateral $\times$ vertical, $F(1,30)=3.42$, $\mathrm{MSE}=0.13, P=0.07$; cue $\times$ visual field $\times$ lateral $\times$ vertical $\times$ caudal, $F(1,30)=3.99, \mathrm{MSE}=0.13, P=0.06$. Only one interaction involving cueing and group approached significance; group $\times$ cue $\times$ visual field $\times$ lateral $\times$ vertical $\times$ caudal, $F(1,30)=2.92, \mathrm{MSE}=0.13$, $P=0.10$.

Although we hesitate to accept the null hypothesis of no group differences in cueing, the overall similarity of the young and older 200-400 ms cueing effects was impressive. Fig. 5 shows that the topography of the cueing effects was very similar between groups, and that each group showed similar differences between the LVF and RVF effects. Fig. 6 shows that cueing effects were very similar between groups, despite considerable differences in overall ERP amplitudes and latencies. Collapsing the 128 electrodes into eight broad regions may obscure more local, intra-region differences [22]. Significant interactions between group and cueing may have arisen if individual electrodes were the unit of analysis, but lacking a prior hypotheses, Type II errors would be likely.

\section{Discussion}

The effects of aging were investigated with ERPs in a visuospatial attention task. A central arrow pointed towards the location of an upcoming lateralized visual target $(75 \%$ valid) or in the opposite direction $(25 \%$ invalid). Both older and young adults were faster discriminating between peripheral targets (circle versus square) following valid cues than invalid cues. An interaction between this cue validity effect and age indicated that the RT difference between valid and invalid trials was larger for older than young subjects (as earlier observed under similar conditions, $[23,25])$.

The observed age by cue validity interaction on RT may be interpreted in several ways. Older adults may allocate more attentional resources than younger adults
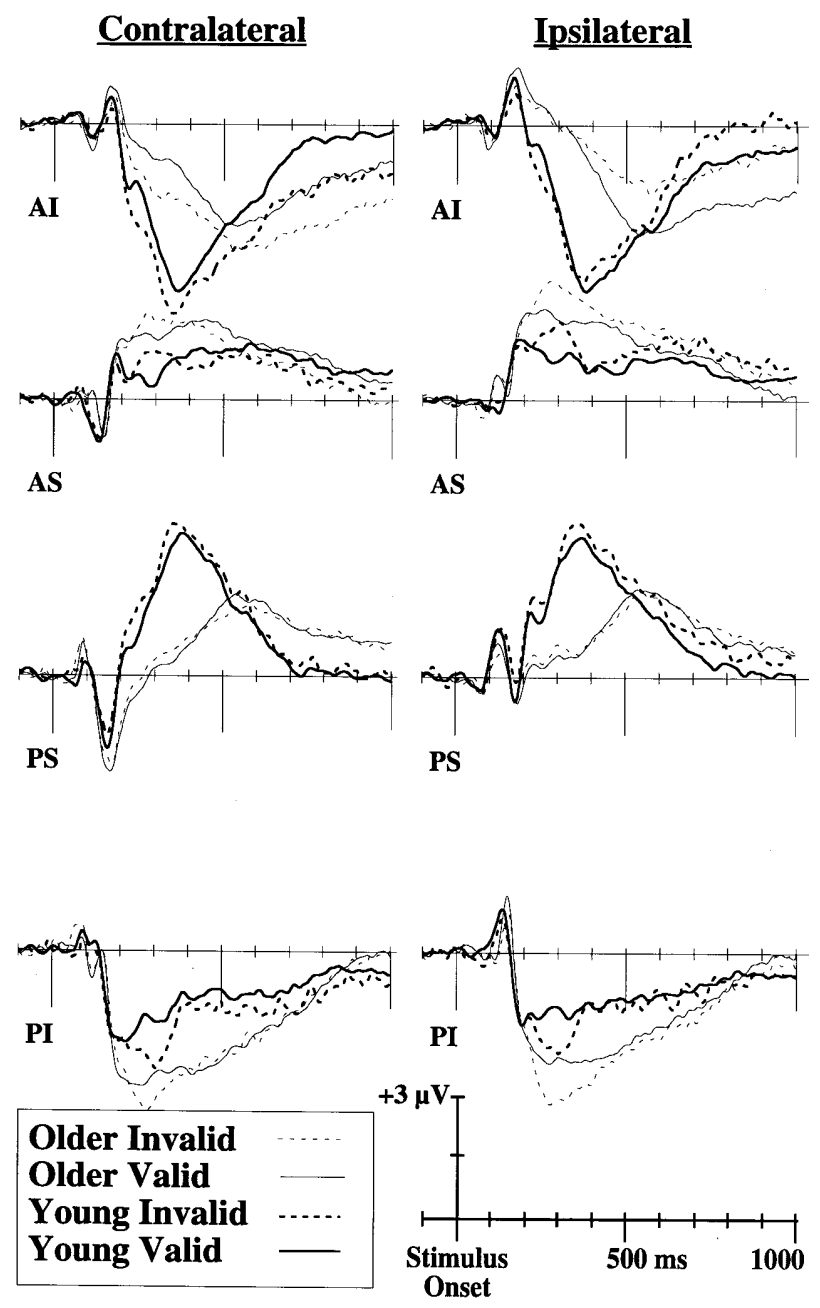

Fig. 6. Grand-average, average-referenced ERPs are channel means within each of the eight spatial regions used for the $200-400 \mathrm{~ms}$ ANOVA (A, anterior, P, posterior, I, inferior, S, superior; see Fig. 1 for locations). Contralateral ERPs (left side) are averaged across right hemisphere ERPs to LVF targets and left hemisphere ERPs to RVF targets. Ipsilateral ERPs (right side) are averaged across right hemisphere ERPs to RVF targets and left hemisphere ERPs to LVF targets. 
(e.g. [25]). ERP analyses would support such a conclusion if ERP differences between valid and invalid conditions were larger for older than young subjects. Alternatively, larger cueing effects for older subjects may be attributable to slower responding (e.g. [38]). The latter explanation is consistent with the observation that young and older validity effects did not differ when they were expressed as a proportion of mean reaction time. However, the true relationship between the invalid-valid difference scores and overall response speed may not be proportional, so proportional scores may not appropriately correct for group differences in overall slowness [8]. If, as suggested by the proportional slowing analysis, older and younger subjects were similarly affected by cue validity, then the ERP validity effects should also be similar across groups.

Cue validity had similar affects on early ERP components for young and older subjects. As earlier reported in studies with young subjects, the amplitude of the P1, $\mathrm{N} 1$, and $\mathrm{Nd} 1$ components differed between valid and invalid conditions [17,41]. There were no significant interactions between age and cue validity for the ipsilateral $\mathrm{P} 1, \mathrm{~N} 1$, or $\mathrm{Nd} 1$. A group by cue type interaction on the contralateral P1 suggested that the P1 was more positive following invalid than valid cues for the older group, but the conditions did not differ for the young group. The older group's contralateral P1 effect was in the opposite direction of most of the earlier reports (e.g. $[14,16,44,41])$. Two earlier studies using peripheral exogenous cues have reported larger P1 amplitudes for invalid than valid trials $[15,29]$. If replicable, the contralateral $\mathrm{P} 1$ cue $\times$ group interaction may indicate an interesting difference between the early selection processes of young and older subjects. However, the unusually early onset of the older subjects' contralateral P1 suggests that their invalid $>$ valid pattern could also be attributable to noisy data.

The ipsilateral P1, contralateral N1, and ipsilateral N1 components were higher amplitude following valid than invalid cues; and this enhancement did not differ between young and older subjects. The similarity of young and older attention effects is particularly striking when juxtaposed with the overall slower latencies of these components in older subjects. The P1 ipsilaterally and the N1 bilaterally reached peak amplitude significantly faster for young than older subjects. This pattern of results is relevant to understanding the neural bases of the attention effects. P1 and N1 validity effects typically are interpreted as reflecting direct modulation of the same neural processes that generate the P1 and N1 components, but it is also possible that the validity effects arise from separate processes that happen to temporally overlap with the P1 and N1. According to the 'sensory gain' hypothesis of ERP attention effects, spatial attention enhances the amplitude of the visual processes generating the components $(\mathrm{P} 1, \mathrm{~N} 1)$ without engaging additional processes [27,40-42]. One line of evidence favoring direct enhancement of the $\mathrm{P} 1$, is the similar timing and scalp distribution of the P1 component and the corresponding valid-invalid ERP differences $[27,42]$. Two studies have supported sensory gain by demonstrating that component latency can be slowed by manipulating target/background contrast, and the latency of valid-invalid differences systematically tracks the peak latency of the corresponding ERP components [33,65]. If attention reflects the operation of processes that are separate from the contrast-sensitive perceptual processes indexed by $\mathrm{P} 1$ and N1, then the latency of the attention effects would not necessarily track the component latency. Both the studies $[33,65]$ observed that P1 latency was slower for low than high contrast targets, and the P1 validity effects were similarly slowed by visual contrast — as would be expected by sensory gain control. Wijers et al.[65] similarly found that N1 peak latency maintained correspondence with N1 validity effects, but Johannes et al.'s [33] contrast manipulation slowed N1 latency without delaying the validity effects. The present results support the sensory gain hypothesis for both the ipsilateral P1, contralateral N1, and ipsilateral N1 because the age-related delays in component latency were accompanied by similar delays in the timing of the attention effects.

The observation that equivalent validity effects were observed between groups despite slower component latency in older subjects is also relevant to theories of cognitive aging that emphasize processing speed. For example, Salthouse's [58] processing-speed theory assumes the quality or quantity of information decreases as processing speed slows. Although the precise relationship between these information processing constructs and ERP characteristics is uncertain, a possible implication of this theory is that such information decreases should dampen the cognitive effects on ERP components that are slowed by aging. In other words, increased P1/N1 latency should decrease the information driving the attention effects on these components, so these components should show weaker attention effects for older (slower) than young (faster) subjects. Instead, the present results suggest that little or no information loss was associated with slowed $\mathrm{P} 1 / \mathrm{N} 1$ latency. In addition to valid-invalid amplitude differences being unaffected age-related slowing, overall P1/ $\mathrm{N} 1$ amplitudes were unaffected by aging. These observations should not be misconstrued as an intended refutation of processing-speed theory, but these results do imply that physiological slowing is not necessarily accompanied by information loss.

The strongest suggestion of cueing deficit in older subjects was observed for P3 amplitude. For young subjects, invalid $\mathrm{P} 3 \mathrm{~s}$ were higher amplitude than valid $\mathrm{P} 3 \mathrm{~s}$ across the 3 midline loci $(\mathrm{Pz}+, \mathrm{Cz}+, \mathrm{Fz}+$; replicating, e.g. $[17,41])$, but the older subjects showed a 
weak validity effect only at $\mathrm{Fz}+$. Taken at face value, the $\mathrm{P} 3$ results could suggest that attentional mechanisms contributing to the $\mathrm{P} 3$ are somewhat weak or deficient in the older subjects. However, we believe that the P3 per se was not affected by attention. ERP cue validity effects were greatest between 200 and $400 \mathrm{~ms}$ for both older and young subjects (see Figs. 5 and 6). For young subjects, the $200-400 \mathrm{~ms}$ validity effect included the early rise of the P3 (peak latency $=392$ $\mathrm{ms}$ ) and overlapped the temporal window chosen for P3 amplitude analyses $(292-492 \mathrm{~ms})$. For older subjects the $200-400$ ms validity effect was prior to the P3 (peak latency $=526 \mathrm{~ms}$; window $=426-626 \mathrm{~ms}$ ). Given the substantial overall similarity between the 200 and 400 $\mathrm{ms}$ validity effects observed for both young and older subjects (see Fig. 5), the present results suggest that the 200-400 ms validity effect can be dissociated from the P3. It appears that young and older subjects engage similar attention-related processes between 200 and 400 $\mathrm{ms}$, and these processes may only coincidentally correspond to the timing of the young P3. This interpretation is consistent with other research showing that the validity effect is not necessarily affected by the same variables as the P3. For example, the P3 validity effect was initially presumed to be attributable to the lower probability of invalid trials [41] because the $\mathrm{P} 3$ is know to be sensitive to target probability $[13,34]$. However, the $\mathrm{P} 3$ validity effect has been observed with peripheral cues when valid and invalid cues are equally probable [15].

The $200-400$ ms validity effect included the Nd2 for both young (220-280 ms) and older subjects (280-340). The finding that $\mathrm{Nd} 2$ amplitude was more negative following valid than invalid cues replicated earlier research [17]. Though the cue by group interaction did not approach significance in the $\mathrm{Nd} 2$ analyses, a group by cue by location interaction suggested a group difference. The three way interaction captured the observation that the $\mathrm{Nd} 2$ validity effect was more frontally distributed for older than young participants. When the entire scalp distribution of the $200-400 \mathrm{~ms}$ validity effect was considered, the older and young subjects did not show significant differences in the distribution of the validity effect (Fig. 5).

In addition to the ERP validity effects that were our primary focus, aspects of the presently observed latency differences are notable. P3 latency is commonly reported to slow with aging (for meta-analytic review, see [52]). Aging effects on the latency of earlier components are not as reliably observed, and many studies focused on P3 latency have not analyzed earlier components. The visual N1 has been reported to be slowed [6] or unaffected $[1,36]$ by aging. Similarly, aging has been reported to slow [6,59] or not influence [36] visual P1 latency. The present results suggested that aging slowed the latency of the ipsilateral P1, contralateral N1, and ipsilateral $\mathrm{N} 1$ as well as the P3. The contralateral P1 latency did not significantly differ between older and younger subjects. Under the present conditions, slowing originated between the contralateral P1 (young $=96$ $\mathrm{ms}$, older $=94 \mathrm{~ms}$ ) and ipsilateral P1 (young $=124 \mathrm{~ms}$, older $=134 \mathrm{~ms}$ ). The experiment had reasonable power $(1-\beta=0.82)$ to detect a contralateral $\mathrm{P} 1$ difference as large as the $10 \mathrm{~ms}$ ipsilateral difference, but the effect warrants replication with more powerful designs. Agerelated latency increase of the ipsilateral, but not the contralateral, P1 suggests that slowing was not attributable to the earliest stages of visual analysis (from retina to contralateral visual cortex) in the present sample.

The initial appearance of age-related ERP slowing between the contralateral and ipsilateral P1s may be related to differences in callosal transfer speed - an interpretation consistent with earlier ERP research and aging research using other methods. Subjects with agenesis of the corpus callosum have shown contralateral $\mathrm{P} 1 \mathrm{~s}$, but not ipsilateral P1s, so callosal transfer appears to intervene between these components $[5,57,60]$. Corpus callosum size decreases $[12,30]$ and behavioral estimates of interhemispheric transfer time increase with age [32]. Furthermore, P3 amplitude may be related to callosal size and transfer speed [28,53], so age-related slowing of interhemispheric transfer speed could have contributed to lower P3 amplitude of older than young subjects $^{2}$.

The present results are limited in at least two respects. First, as reviewed in the introduction, validity effects and their sensitivity to aging in Posner's task interact with a number of experimental variables including SOA, cue type, number of response alternatives. Therefore, these results may not generalize to other conditions. Second, these results are limited by uncertainties about the functional significance of the ERP effects. The P1 and N1 effects are generally thought to be related to selection at the level of early perceptual processing (reviewed in $[18,43]$ ). The $\mathrm{Nd} 1$ is not specific to the visual modality and may reflect parietal lobe mechanisms related to location expectancy [18]. There has been little earlier speculation concerning the functional correlates of the $\mathrm{Nd} 2$. The present results suggest that it may be useful to consider effects that are temporally (200-400 ms) and spatially broader (Fig. 5) than earlier reported $\mathrm{Nd} 2$ effects (e.g. $\mathrm{Pz}, \mathrm{Cz}, \mathrm{Fz}$; 220-280 ms; [17]).

\footnotetext{
${ }^{2}$ Callosal size and interhemispheric transfer speed have been reported to vary with sex and handedness [12,30,32]. Therefore, it is notable that all of the present subjects were right handed, and the two age groups had similar sex distributions (nine of the 16 older subjects were female; seven of the 16 young subjects were female). P1 latency analyses were repeated with sex as between subjects variable, but sex-related effects did not approach significance.
} 
In summary, young and older subjects showed similar electrophysiological responses to cue validity in the present visuospatial attention experiment. For earlier components (P1, N1, Nd1), cue validity had similar effects on component amplitude even though component latency was significantly slowed by aging. The consistent age-related slowing of these early ERP components and validity effects supports the idea that ERP validity effects reflect the direct enhancement of early visual processes (i.e. 'sensory gain' $[27,42]$ ). The broadly distributed, 200-400 ms validity effect showed a similar time course, spatial distribution, and amplitude modulation in both age groups (see Fig. 5) despite striking differences in overall waveform latency and morphology (see Fig. 6). The temporally age-invariant 200-400 ms validity effect suggests that validity effects coincidentally overlap with the P3 in young subjects, but do not reflect a direct attentional modulation of the neural generators of the P3. Finally, finding that age-related slowing did not affect the contralateral P1, but increased the latency of all components after and including the ipsilateral $\mathrm{P} 1$, suggests that the pre-callosal stages of visual processing may not have been adversely affected by aging.

\section{Acknowledgements}

The present research was supported by a pilot grant from the Alzheimer Center of University Hospitals and Case Western Reserve University (National Institute of Aging, AG08012); a grant from the American Federation for Aging Research; a grant from Phillip Morris, Inc., USA; and a Research Initiation Grant from CWRU. Thanks to A. David, J. Johnson, S. Klein, R. Spinks, J. Teichman, and Paul Witeczek for research assistance; and Electrical Geodesics Inc. for technical support.

\section{References}

[1] Beck EC, Swanson C, Dustamn RE. Long latency components of the visually evoked potential in man: effects of aging. Experimental Aging Research 1980;6:523-45.

[2] Bertrand O, Perin F, Pernier J. A theoretical justification of the average reference in topographic evoked potential studies. Electroencephalography and Clinical Neuroscience 1985;62:462-4.

[3] Brinley JF. Cognitive sets, speed and accuracy of performance in the elderly. In: Welford AT, Birren JE, editors. Behavior, Aging, and the Nervous System. Springfield, IL: Thomas, 1965:114-49.

[4] Brodeur DA, Enns JT. Covert visual orienting across the lifespan. Canadian Journal of Experimental Psychology 1997;51:20-35.

[5] Brown WS, Jeeves MA, Dietrich R, Burnison DS. Bilateral field advantage and evoked potential interhemispheric transmission in commissurotomy and callosal agenesis. Neuropsychologia 1999;37:1165-80.
[6] Celesia GG, Daly RF. Effects of aging on visual evoked responses. Archives of Neurology 1977;34:403-7.

[7] Cerella J. Age and information processing rates in the elderly. In: Birren JE, Schaie KW, editors. Handbook of the Psychology of Aging, third ed. New York: Academic Press, 1990:201-21.

[8] Chapman LJ, Chapman JP, Curran T, Miller MB. Do children and the elderly show heightened semantic priming? How to answer the question. Developmental Review 1994;14:159-85.

[9] Curran T. The electrophysiology of incidental and intentional retrieval: ERP old/new effects in lexical decision and recognition memory. Neuropsychologia 1999;37:771-85.

[10] Curran T, Tucker DM, Kutas M, Posner MI. Topography of the N400: brain electrical activity reflecting semantic expectation. Electroencephalography and Clinical Neurophysiology 1993;88: 188-209.

[11] Dien J. Issues in the application of the average reference: review, critiques, and recommendations: behavior research methods. Instruments and Computers 1998;30:34-43.

[12] Driesen NR, Raz N. The influence of sex, age, and handedness on corpus callosum morphology: a meta-analysis. Psychobiology 1995;23:240-7.

[13] Duncan-Johnson CC, Donchin E. On quantifying surprise: the variation of event-related potentials with subjective probability. Psychophysiology 1977;14:456-67.

[14] Eimer M. Spatial cueing, sensory gating and selective response preparation: an ERP study of visuo-spatial orienting. Electroencephalography and Clinical Neurophysiology 1993;88:408-20.

[15] Eimer M. An ERP study on visual-spatial priming with peripheral onsets. Psychophysiology 1994;31:154-63.

[16] Eimer M. Sensory gating' as a mechanism for visuospatial orienting: electrophysiological evidence from trial-by-trial cuing experiments. Perception and Psychophysics 1994;55:667-75.

[17] Eimer M. ERP modulations indicate the selective processing of visual stimuli as a result of transient and sustained spatial attention. Psychophysiology 1996;33:13-21.

[18] Eimer M. Mechanisms of visuospatial attention: evidence from event-related brain potentials. Visual Cognition 1998;5:257-86.

[19] Folk CL, Hoyer WJ. Aging and shifts of visual spatial attention. Psychology and Aging 1992;7:453-65.

[20] Folstein MF, Folstein SE, McHugh PR. Mini-mental state: a practical method for grading the cognitive state of patients for the clinician. Journal of Psychiatric Research 1975;12:189-98.

[21] Friedman D. Cognition in the elderly: an event-related potential perspective. In: Boller F, Grafman J, editors. Handbook of Neuropsychology, vol. 10. Amsterdam: Elsevier, 1995:213-40.

[22] Gevins A, Cutillo B, Smith ME. Regional modulation of high resolution evoked potentials during verbal and non-verbal matching tasks. Electroencephalography and Clinical Neurophysiology 1995;94:129-47.

[23] Greenwood PM, Parasuraman R, Haxby JV. Changes in visuospatial attention over the adult lifespan. Neuropsychologia 1993;31:471-85.

[24] Harter MR, Miller SL, Price NJ, LaLonde ME, Keyes AL. Neural processes directing attention. Journal of Cognitive Neuroscience 1989;1:223-37.

[25] Hartley AA, Kieley JM, Slabach EH. Age differences and similarities in the effects of cues and prompts. Journal of Experimental Psychology: Human Perception and Performance 1990;16:523-38.

[26] Heinze HJ, Mangun GR, Burchert W, Hinrichs H, Scholz M, Münte TF, Gös A, Scherg M, Johannes S, Hundeshagen H, Gazzaniga MS, Hillyard SA. Combined spatial and temporal imaging of brain electrical activity during visual selective attention in humans. Nature 1994;372:543-6.

[27] Hillyard SA, Vogel EK, Luck SJ. Sensory gain control (amplification) as a mechanism of selective attention: electrophysiological and neuroimaging evidence. Philosophical Transactions of the 
Royal Society of London-Series B: Biological Sciences 1998;353:1257-70.

[28] Hoffman LD, Polich J. P300, handedness, and corpus callosal size: gender, modality, and task. International Journal of Psychophysiology 1999;31:163-74.

[29] Hopfinger JB, Mangun GR. Reflexive attention modulates processing of visual stimuli in human extrastriate cortex. Psychological Science 1998;9:441-7.

[30] Hopper KD, Patel S, Cann TS, Wilcox T, Schaeffer JM. The relationship of age, gender, handedness, and sidedness to the size of the corpus callosum. Academic Radiology 1994;1:243-8.

[31] Hoyer WJ, Familant ME. Adult age differences in the rate of processing expectancy information. Cogntive Development 1987;2:59-70.

[32] Jeeves MA, Moes P. Interhemispheric transfer time differences related to aging and gender. Neuropsychologia 1996;34:627-36.

[33] Johannes S, Munte TF, Heinze HJ, Mangun GR. Luminance and spatial attention effects on early visual processing. Brain research. Cognitive Brain Research 1995;2:189-205.

[34] Johnson RJ. The amplitude of the P300 component of the event-related potential: review and synthesis. In: Ackles PK, Jennings JR, Coles MGH, editors. Advances in Psychophysiology, vol. III. Greenwich, CT: Jai Press, 1988:69-137.

[35] Jonides J. Voluntary versus automatic control over the mind's eye's movement. In: Long J, Baddeley A, editors. Attention and Performance IX. Hillsdale, NJ: Erlbaum, 1981:187-203.

[36] Kutas M, Iragui V, Hillyard SA. Effects of aging on event-related brain potentials (ERPs) in a visual detection task. Electroencephalography and Clinical Neurophysiology 1994;92:126-39.

[37] Lehman D, Skrandies W. Spatial analysis of evoked potentials in man - a review. Progress in Neurobiology 1985;23:227-50.

[38] Lincourt AE, Folk CL, Hoyer WJ. Effects of aging on voluntary and involuntary shifts of attention. Aging, Neuropsychology and Cognition 1997;4:290-303.

[39] Mangun GR. Neural mechanisms of visual selective attention. Psychophysiology 1995;32:4-18.

[40] Mangun GR, Hillyard SA. The spatial allocation of visual attention as indexed by event-related brain potentials. Human Factors 1987;29:195-211.

[41] Mangun GR, Hillyard SA. Modulation of sensory-evoked brain potentials indicate changes in perceptual processing during visualspatial priming. Journal of Experimental Psychology: Human Perception and Performance 1991;17:1057-74.

[42] Mangun GR, Hillyard SA, Sj L. Electrocortical substrates of visual selective attention. In: Meyer DE, Kornblum S, editors. Attention and Performance XIV. Cambridge: MIT Press, 1993:219-34.

[43] Mangun GR, Hillyard SA. Mechanisms and models of selective attention. In: Rugg MD, Coles MGH, editors. Electrophysiology of Mind. New York: Oxford University Press, 1995:40-85.

[44] Mangun GR, Buck LA. Sustained visual-spatial attention produces costs and benefits in response time and evoked neural activity. Neuropsychologia 1998;36:189-200.

[45] Mangun GR, Hopfinger JB, Kussmaul CL, Fletcher E, Heinze HJ. Covariations in ERP and PET measures of spatial selective attention in human extrastriate visual cortex. Human Brain Mapping 1997;5:273-9.

[46] Muller HJ, Rabbit PMA. Reflexive and voluntary orienting of visual attention: time course of activism and resistance to interruption. Journal of Experimental Psychology: Human Perception and Performance 1989;15:315-30.

[47] Myerson J, Hale S, Wagstaff D, Poon LW, Smith GA. The information loss model: a mathematical theory of age-related cognitive slowing. Psychological Review 1990;97:475-87.

[48] Nunez PL. Electrical Fields of the Brain. New York: Oxford University Press, 1981.

[49] Parasuraman R, editor. The Attentive Brain. Cambridge, MA: MIT Press, 1998.

[50] Pashler HE. The Psychology of Attention. Cambridge, MA: MIT Press, 1998.

[51] Picton TW, Lins OG, Scherg M. The Recording and analysis of event-related potentials. In: Boller F, Grafman J, editors. Handbook of Neuropsychology, vol. 10. Amsterdam: Elsevier, 1995:373.

[52] Polich J. Meta-analysis of P300 in normative aging studies. Psychophysiology 1996;33:334-53.

[53] Polich J, Hoffman LD. P300 and handedness: on the possible contribution of corpus callosal size to ERPs. Psychophysiology 1998;35:497-507.

[54] Posner MI. Orienting of attention. Quarterly Journal of Experimental Psychology 1980;32:3-25.

[55] Posner MI, Cohen YA. Components of visual attention. In: Bouma H, Bouwhuis DG, editors. Attention and Performance, vol. 10. Hillsdale, NJ: Erlbaum, 1984:531-54.

[56] Posner MI, Nissen MJ, Ogden WC. Attended and unattended processing modes: the role of set for spatial location. In: Pick HL, Saltzman IJ, editors. Modes of Perceiving and Processing Information. Hillsdale, NJ: Erlbaum, 1978:137-57.

[57] Rugg MD, Milner AD, Lines CR. Visual evoked potentials to lateralised stimuli in two cases of callosal agenesis. Journal of Neurology, Neurosurgery and Psychiatry 1985;48:367-73.

[58] Salthouse TA. The processing speed theory of adult age differences in cognition. Psychological Review 1996;103:403-28.

[59] Sokol S, Moskowitz A, Towle VL. Age-related changes in the latency of the visual evoked potential: influence of check size. Electroencephalography and Clinical Neurophysiology 1981;51:559-62.

[60] Speiser AH, Tucker DM, McDougal L, Murias M, Brown W. Absent electrical responses in the unstimulated hemisphere in agenesis of the corpus callosum,. (unpublished).

[61] Srinivasan R, Nunez PL, Silberstein RB, Tucker DM, Cadusch PJ. Spatial sampling and filtering of EEG with spline - Laplacians to estimate cortical potentials. Brain Topography 1996;8:355-66.

[62] Tellinghuisen DJ, Zimbra LD, Robin DA. Endogenous visuospatial precuing effects as a function of age and task demands. Perception and Psychophysics 1996;58:947-58.

[63] Tucker DM. Spatial sampling of head electrical fields: the geodesic sensor net. Electroencephalography and Clinical Neurophysiology 1993;87:154-63.

[64] Tucker DM, Liotti M, Potts GF, Russell GS, Posner MI. Spatiotemporal analysis of brain electrical fields. Human Brain Mapping 1994;1:134-52.

[65] Wijers AA, Lange JJ, Mulder G, Mulder LJ. An ERP study of visual spatial attention and letter target detection for isoluminant and nonisoluminant stimuli. Psychophysiology 1997;34:553-65.

[66] Winer BJ. Statistical Principles in Experimental Design, 2nd ed. New York: McGraw-Hill, 1971.

[67] Yagaguchi S, Tsuchiya H, Kobayashi S. Electrophysiologic correlates of age effects on visuospatial attention shift. Cognitive Brain Research 1995;3:41-9.

[68] Yantis S, Jonides J. Abrupt visual onsets and selective attention: Voluntary versus automatic allocation. Journal of Experimental Psychology: Human Perception and Performance 1990;10:601-21. 